\title{
Editorial
}

\section{Spina bifida care, education, and research: A multidisciplinary community in a global context}

\author{
Jonathan Castillo ${ }^{\mathrm{a}, *}$, Heidi Castillo ${ }^{\mathrm{a}}$, Judy K. Thibadeau ${ }^{\mathrm{b}}$ and Tim Brei ${ }^{\mathrm{b}, \mathrm{c}}$ \\ ${ }^{a}$ Meyer Center for Developmental Pediatrics, Department of Pediatrics, Texas Children's Hospital and the Baylor \\ College of Medicine, Houston, TX, USA \\ ${ }^{\mathrm{b}}$ Spina Bifida Association, Arlington, VA, USA \\ ${ }^{\mathrm{c}}$ Department of Pediatrics, Division of Developmental Medicine, Seattle Children's Hospital and the University \\ of Washington School of Medicine, Seattle, WA, USA
}

\begin{abstract}
Worldwide neural tube defects, such as encephalocele and spina bifida (SB), remain a substantial cause of the global burden of disease; and in the US, Latinos consistently have a higher birth prevalence of SB compared with other ethnic groups. From limited access and fragmented care, to scarcely available adult services, many are the challenges that besiege those living with SB. Thus, to provide inclusion and active involvement of parents of children and adults with SB from all communities, innovative approaches will be required, such as community-based participatory research and culturally competent learning collaboratives. Promisingly, the Spina Bifida Community-Centered Research Agenda was developed by the community of people living with SB through the Spina Bifida Association (SBA). Additionally, the SBA will host the Fourth World Congress on Spina Bifida Research and Care in March of 2023. Just as the SBA is clearly committed to this population, the Journal of Pediatric Rehabilitation Medicine will continue to serve as a catalyst for SB care, education, and research across the SB population in a global context.
\end{abstract}

Keywords: Myelomeningocele, community-based participatory research, care coordination, minority health, health disparities, learning collaboratives, global health

Worldwide, in spite the attainments of wideranging folic acid fortification programs, neural tube defects (NTDs) remain a substantial cause of the pediatric global burden of disease [1]. From limited access and fragmented care, to scarcely available adult services, many are the challenges that besiege those living with spina bifida (SB) across their lifespan. Yet, there are equally many professionals who are dedicated to the care of this population. While upholding human dignity, their passion is an encouragement.

\footnotetext{
${ }^{*}$ Corresponding author: Jonathan Castillo, Meyer Center for Developmental Pediatrics, 8080 North Medical Drive, Suite 180, Houston, TX 77054, USA. Tel.: +1 832822 3400; Fax: +1 832 825 3399; E-mail: jcporter@texaschildrens.org.
}

They are compassionately committed, not only to those they serve, but also to developing and upholding best clinical practices in the multidisciplinary care they provide [2].

This new generation of clinicians, who usher in a new era of dynamic and prolific inquiry, are inclusive of the voices and experiences of those they serve. With the COVID-19 pandemic as background, they also synchronously recognize, as though harmonized by a single melody, that we live in a globalized community. For just as the incidence of SARS-CoV-2 has had a borderless impact on global public health, so too childhood-onset disabilities continue to have widespread significance. Fortuitously, following the 
Third World Congress of Spina Bifida Research and Care in 2017, the Journal of Pediatric Rehabilitation Medicine (JPRM) emerged as a global platform for the publication and dissemination of SB-related enquiry. Thus previously, JPRM published numerous articles on SB care, from works reflecting the "Guidelines for the Care of People with Spina Bifida," to research studies conducted through the multicenter National Spina Bifida Patient Registry [3, 4].

Now through this sixth special issue on SB care and research, JPRM showcases innovative new work. In this issue, from self-management topics (e.g., bowel/bladder care and pain management) to access and care coordination, many are the investigational areas written about through state-of-the-art studies. Additionally, avant-garde issues (e.g., reproductive health and COVID-19 immunization uptake) are also conceptualized and thoughtfully discussed.

While globally NTDs remain a significant cause of the pediatric disease burden, in the US Latinos consistently have a higher birth prevalence of both anencephaly and SB compared with other ethnic groups [5]. To effectively serve this fast growing vulnerable population, building trust among clinicians, researchers, and community members is needed. As with any stakeholder engagement activity, far-seeing effort must be invested to foment equitable collaboration and shared decision-making. Consequently, it has been noted that "fresh approaches will be required, such as SB community-based participatory research and culturally competent learning collaboratives, to develop respectful partnerships reflective of all lived experiences" [6].

Promisingly, the Spina Bifida Association is committed to the inclusion and active involvement of parents of children and adults with SB in determining how and for what to advocate, what and for whom education is needed, what support is needed and how it can be delivered most effectively, and on which topics investigation is warranted. Accordingly, the 2016-2021 Spina Bifida Community-Centered Research Agenda was developed by the community of people living with SB. In November 2021, a Research Workshop was held during which the Community-Centered Research Agenda was introduced to more than 200 participants. In addition, collaborations were initiated in order to address the investigational priorities of the community.
Nevertheless, care for people with SB does not improve without ongoing education and research. Just as JPRM is committed to publishing a volume each year focused on inquiry on SB, the Spina Bifida Association is invested in continuing to host an ongoing forum for presenting the latest SB research. Therefore, the Fourth World Congress on Spina Bifida Research and Care will be held March 23-25, 2023. Moreover, the global SB investigational community looks forward to the call for abstracts to open in the spring of 2022. This meeting will provide an opportunity for health care professionals from around the world to present the latest in basic science, clinical and translational research and build collaborations for future exploration.

While the Spina Bifida Association is committed to this population, the JPRM will continue to serve as a catalyst for SB care, education, and research, across the multidisciplinary SB community in a global context and well into the future [7].

\section{References}

[1] Yacob A, Carr CJ, Foote J, Scullen T, Werner C, Mathkour M, et al. The Global Burden of Neural Tube Defects and Disparities in Neurosurgical Care. World Neurosurg. 2021;149:e803-e820. doi: 10.1016/j.wneu.2021.01.096

[2] Thibadeau J, Walker WO, Castillo J, Dicianno BE, Routh JC, Smith KA, et al. Philosophy of care delivery for spina bifida. Disabil Health J. 2020;13(2):100883. doi: 10.1016/j.dhjo.2019.100883

[3] Dicianno BE, Beierwaltes P, Dosa N, Raman L, Chelliah J, Struwe S, et al. Scientific methodology of the development of the Guidelines for the Care of People with Spina Bifida: An initiative of the Spina Bifida Association. Disabil Health J. 2020;13(2):100816. doi: 10.1016/j.dhjo.2019.06.005

[4] Castillo J, Lupo PJ, Tu DD, Agopian AJ, Castillo H. The National Spina Bifida Patient Registry: A Decade's journey. Birth Defects Res. 2019;111(14):947-957. doi: 10.1002/bdr2.1407

[5] Williams J, Mai CT, Mulinare J, Isenburg J, Flood TJ, Ethen $\mathrm{M}$, et al. Updated estimates of neural tube defects prevented by mandatory folic Acid fortification - United States, 19952011. MMWR Morb Mortal Wkly Rep. 2015;64(1):1-5.

[6] Castillo J, Castillo H. Global health and chronic noncommunicable conditions: Spina bifida care across a worldwide community. J Pediatr Rehabil Med. 2017;10(34):167-168. doi: 10.3233/PRM-170471

[7] Brei TJ. The future of the multidisciplinary clinic. ScientificWorldJournal. 2007;7:1752-6. doi: 10.1100/tsw.2007.254 